\title{
Identification of population substructure among Jews using STR markers and dependence on reference populations included
}

\author{
Jennifer B Listman 1, Deborah Hasin 3,7,8, Henry R Kranzler4, Robert T Malison 1,2, Apiwat Mutirangura5, \\ Atapol Sughondhabirom5 ${ }^{5}$ Efrat Aharonovich33, Baruch Spivak ${ }^{6}$ and Joel Gelernter*1,2,,10
}

\begin{abstract}
Background: Detecting population substructure is a critical issue for association studies of health behaviors and other traits. Whether inherent in the population or an artifact of marker choice, determining aspects of a population's genetic history as potential sources of substructure can aid in design of future genetic studies. Jewish populations, among which association studies are often conducted, have a known history of migrations. As a necessary step in understanding population structure to conduct valid association studies of health behaviors among Israeli Jews, we investigated genetic signatures of this history and quantified substructure to facilitate future investigations of these phenotypes in this population.

Results: Using 32 autosomal STR markers and the program STRUCTURE, we differentiated between Ashkenazi (AJ, $N=$ 135) and non-Ashkenazi (NAJ, $N=226$ ) Jewish populations in the form of Northern and Southern geographic genetic components (AJ north 73\%, south 23\%, NAJ north 33\%, south 60\%). The ability to detect substructure within these closely related populations using a small STR panel was contingent on including additional samples representing major continental populations in the analyses.

Conclusions: Although clustering programs such as STRUCTURE are designed to assign proportions of ancestry to individuals without reference population information, when Jewish samples were analyzed in the absence of proxy parental populations, substructure within Jews was not detected. Generally, for samples with a given grandparental country of birth, STRUCTURE assignment values to Northern, Southern, African and Asian clusters agreed with mitochondrial DNA and Y-chromosomal data from previous studies as well as historical records of migration and intermarriage.
\end{abstract}

\section{Background}

The genetics of Jewish populations, particularly that of Ashkenazi Jews, has been studied extensively to answer questions of human evolutionary, historical, and medical significance [1-11]. Human evolutionary or anthropological studies have typically focused on mitochondrial DNA (mtDNA) or Y-chromosomal data, because the absence of recombination in these regions of the genome allows researchers to infer past human behaviors and evolutionary events such as migrations, founder events, population bottlenecks or expansions, relative male and female con-

\footnotetext{
* Correspondence: joel.gelernter@yale.edu

${ }^{1}$ Department of Psychiatry, Yale University School of Medicine, New Haven, CT, USA

Full list of author information is available at the end of the article
}

tributions to an admixed population, marriage practices, and mode of transmission of languages [12-15]. However, medical research necessitates the use of autosomal data. The depth of data collection and the necessary characterization of subpopulations to control for population stratification during case-control association studies provide a unique resource to augment mtDNA and Y-chromosomal studies and to facilitate the investigation of selection events. For population groups in which group identification is based on cultural practices rather than geographic origin (such as religion for the Jews or Spanish language for Hispanics), the hazard in neglecting such structure may be particularly great in medical genetics studies [1619]. 
Y-chromosomal and mtDNA studies of Jewish populations and their local host populations have, at times, provided conflicting results, but can be summarized as supporting the following: 1 . Almost all Jewish populations are derived from Middle Eastern ancestral populations $[3,8,11,20-23] ; 2$. Bottleneck events have had an effect on the gene pools of Jewish populations [2, 4-6, 21]; 3 . Local female contribution was significant in the establishment of Yemenite, Ethiopian, and Indian Jewish populations [6]; 4. Local male contribution has been less significant for the establishment of most Jewish populations [23], but may have contributed more to Ashkenazi than to non-Ashkenazi populations $[3,8,20,22]$.

Several large-scale studies using autosomal markers demonstrated substructure among European populations, specifically non-Jewish Northern European, nonJewish Southern European, and Ashkenazi Jews [24-26]. Additionally, based on haplotype analysis, recent mtDNA surveys of Ashkenazi and non-Ashkenazi Jewish populations and non-Jewish host populations demonstrated substructure among Jewish populations [6,27]. Although Jewish populations other than Yemenite, Ethiopian, and Indian have not been entirely endogamous, local admixture from host populations, the amount of which varies among populations, has generally occurred at low levels. These historical events may contribute to population structure and stratification that should be taken into consideration in the analysis of data from association studies.

Using thousands of SNPs and principal components analysis (PCA), Seldin et al [25], Price et al [24], and Tian et al [26] found "Northern" and "Southern" components in non-Jewish European populations, which followed a gradient from Northwest Europe to Southeast Europe or North to South, depending on the SNPs used. However, they also reported that both Ashkenazi and Sephardic Jewish samples showed, on average, more than $85 \%$ ancestry from the "Southern" component, regardless of grandparental country of birth. They concluded that this reflects a Middle Eastern origin of both Southeast Europeans and Ashkenazi Jews, which both admixed subsequently to varying extents with populations already occupying Europe. A recent study analyzing a large set of autosomal SNPs [10] using PCA demonstrated that not only is it possible to cluster Ashkenazi Jews separately from non-Jewish Europeans but also that the number of Ashkenazi Jewish grandparents determined where a sample fell on the PCA plot relative to non-Jewish Europeans. Recently, using a large number of STRs and several clustering methods, Kopelman et al [28] showed that four Jewish populations (Tunisian, Moroccan, Turkish, and Ashkenazi) clustered together and intermediate to other European and Middle Eastern populations. In all cases, the authors attributed these clustering patterns to the partial and shared Middle Eastern ancestry of Jews.
Middle Eastern ancestry may be a common factor among Jewish populations; however, the majority of Jewish populations have been located outside of the Middle East for up to 2000 years. As is the case with other highly mobile human populations there has been historically documented gene flow between Jewish populations and local host populations. In addition, because these are populations defined, in part, by religion, gene flow into Jewish populations is a product of conversion as well as marriage. Thus, there should be genetic admixture in Jewish subpopulations that reflects, in part, their migratory histories and may contribute to current genetic differences among Jewish populations. It is known that detecting and quantifying recent admixture is dependent on the time since divergence of the putative parental populations as well as the number and information content of markers. Because clustering algorithms are also dependent on the relative differences between populations, the context of a sample in a given analysis (i.e., the extent of its difference from samples of other populations included in the analysis) can affect clustering patterns. This aspect of the process of population substructure detection may be overlooked in case control association studies and may affect results if not taken into consideration. Based on this, we hypothesized that the presence or absence of putative parental populations in a STRUCTURE analysis would affect the ability to detect substructure in Jewish populations and differences between Jewish populations.

To address this question thoroughly prior to conducting association studies of health behaviors among Israeli Jews, we examined population structure in Jewish populations of European, African, Middle Eastern, Central and South Asian origin. We genotyped 526 subjects, recruited in Israel, with 32 genome-wide unlinked microsatellite markers (STRs). To identify potential population structure in the Jewish population being studied, we also genotyped 254 individuals from self-identified Chinese, Thai, Ethiopian Jewish, African American, and European American samples using the same markers. The Jewish populations sampled here are not comprised of various percentages of discreet ancestral populations. Our premise is that Jewish populations originated in the Middle East but, subsequent to and in the course of long-range migrations, accumulated input from local host populations, each with its own migratory history. We include in our analysis genotypic data from present-day populations whose ancestry serves as a proxy for those populations that might have contributed once Jewish populations migrated out of the Middle East. Our results are of interest both to infer unknown and correlate with known aspects of Jewish history and for their theoretical implications for detecting substructure in seemingly homogenous populations. They are also of important applied interest for studying health-related phenotypes in our 
sample of Israeli Jews. To our knowledge, this is the first study to incorporate proxy parental groups into analysis of structure of a Jewish sample, as well as the first to investigate variation among and ancestry of world-wide Jewish populations with autosomal markers.

Each of the Israeli subjects provided self-reported country of birth, country of birth of parents and grandparents, world region of family origin (not necessarily the same as country of birth of grandparents), whether they considered themselves to be Ashkenazi (as defined by respondents), Sephardic (similarly self-defined), mixed, other or none, and whether they, their parents, and grandparents had been born Jewish (also self-defined). A common practice in the medical and non-medical literatures is to subsume Jews of Spanish, Balkan, Middle Eastern, African, and Asian descent under the term "Sephardic", but since this term implies Spanish origin, it is imprecise and unclear. Further, due to continuous changes in the acceptability and applicability of the term, "Sephardic" among Israelis [29,30], medical and genetic studies involving Israeli participants increasingly refer to subjects as either "Ashkenazi" (AJ) or "non-Ashkenazi" (NAJ) [31-34]. Below, we also follow that nomenclature. This expands on work we first presented in 2008 [35].

\section{Results}

\section{Population Differentiation: group affiliation}

When there is no detectable substructure in a sample, after using the program STRUCTURE $2.2[36,37]$ each individual will have nearly equal assignment values to each assumed population, giving the appearance that each individual is entirely and nearly equally admixed; when this pattern is observed, the result is not meaningful in terms of actual detection of structure [38]. When the mixed Jewish sample was analyzed alone, using STRUCTURE, the assignment values for $\mathrm{K}=2$ through $\mathrm{K}$ $=4$ yielded no detectible substructure (Fig. 1a). When EA, AA and Asian samples were added to the analysis (with the effect of establishing parental populations for clustering), AJ was assigned to Southern $0.23 \%$, Northern $0.73 \%$, Asian $0.02 \%$, and African $0.01 \%$, NAJ was assigned to Southern $0.60 \%$, Northern $0.33 \%$, Asian $0.03 \%$, and African $0.03 \%$, and ANAJ was assigned to Southern $0.34 \%$, Northern $0.62 \%$, Asian $0.02 \%$, and African $0.02 \%$ (Fig. 1b). In this case, the best $\mathrm{K}$ for the data based on the StructureSum algorithm [39] was 4. Two-sided two sample t-tests via Monte-Carlo permutation with 10,000 repetitions showed significant differences between $\mathrm{AJ}$ and NAJ for individual Northern and Southern assignment values ( $\mathrm{p}<2.2 \mathrm{e}-16$ in both cases) but not for Asian ( $\mathrm{p}=$ 0.6387 ) or African ( $\mathrm{p}=0.1182)$ assignment values (table 1).
Population Differentiation: grandparental country of birth

Within the Jewish-Israeli sample, for sets of individuals reporting four grandparents from the same country of birth, we averaged percent ancestry from Northern, Southern, Asian, and African components to evaluate possible geographic influences on ancestry components. We found that, in many cases, evidence of admixture with host populations based on our autosomal data confirmed the results of previous mtDNA or Y-chromosome studies $[6,20,22,23,40]$ (Fig. 2 and table 2). However, the variance for Northern and Southern components within each country of birth was high with the exception of individuals with all four grandparents from Germany or all four grandparents from the Ukraine.

\section{Hardy Weinberg Equilibrium (HWE)}

No population showed significant deviation from HWE expectations over all loci. Following application of a Bonferroni correction to correct for multiple testing (requiring a $\mathrm{p}$ value of $0.05 / 32=0.00156$ for significance), no $\mathrm{p}$ values for individual loci are significant.

\section{Marker Information Content}

The tetranucleotide and dinucleotide markers had similar average non-Ashkenazi/Ashkenazi delta values $(0.133$ and 0.130 , respectively). Overall, the delta values for this marker panel (0.131) would not indicate a robust ability to differentiate between these two populations but the results of this study (considering the consistency of the observed ancestry coefficients with known geography and previous studies) show their utility for this purpose nonetheless (table 3).

\section{Discussion}

Using 32 autosomal STR markers and the program STRUCTURE, we differentiated between Ashkenazi and non-Ashkenazi Jewish populations in the form of Northern and Southern genetic components. We also demonstrated the utility of including reference populations when attempting to detect population substructure within closely related populations. Notably, we revealed substructure among Jews using a small STR panel, but only when additional samples with ancestry from African, Asian, and European continental populations were included in analyses. The recent study by Kopelman et al [28] used genotypic data from considerably more STRs than our study; however, we found that inclusion of additional populations and high information content per marker apparently compensated, in part, for the relatively low number of markers we used. We also suggest that the clustering patterns in their study may have been somewhat altered if they had not, in effect, assumed that Jewish populations were a product of Middle Eastern and European ancestry, only. Our results indicate that only with the inclusion of world-wide samples is it possible to 


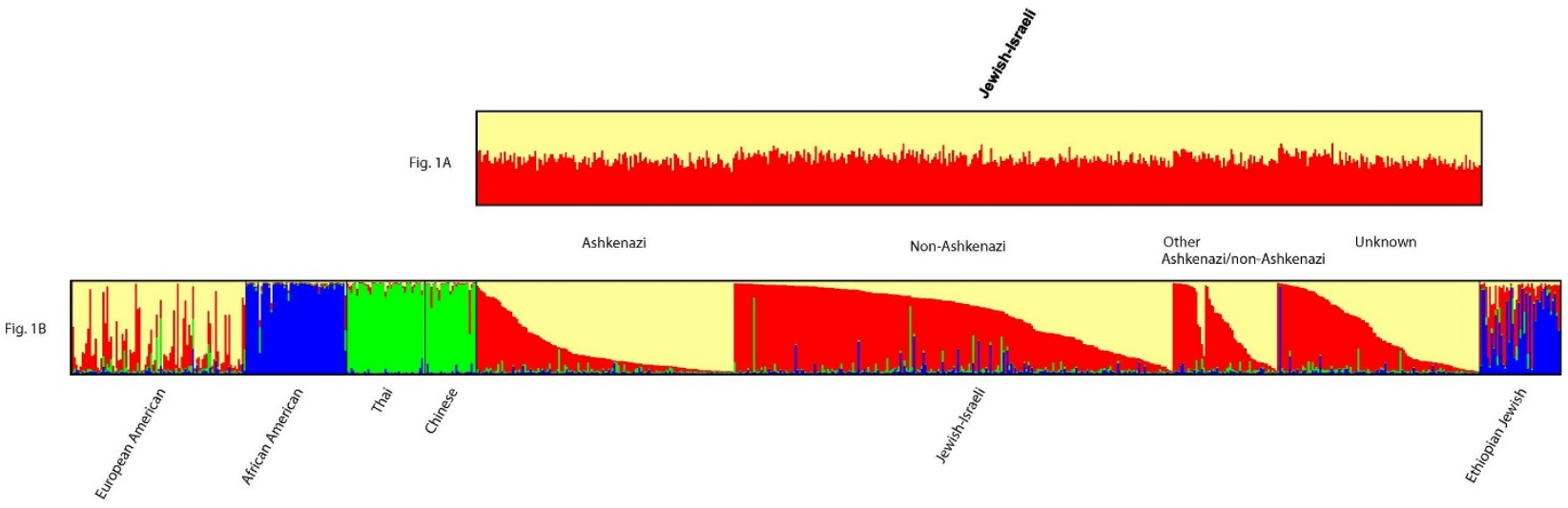

Figure 1 STRUCTURE plots with and without world-wide samples. a. STRUCTURE plot of European-American (EA) and Jewish-Israeli samples when $\mathrm{K}=2$. Each vertical line represents an individual with ancestry components shown as different colors. Self-identified group affiliation (Ashkenazi, Non-Ashkenazi, Other, Ashkenazi/non-Ashkenazi (for individuals with one parent from each group), or Unknown) is listed for Jewish-Israeli samples in between Fig. 1a and Fig. 1b. The order of Jewish-Israeli individuals is the same in figures 1a and 1b. b. STRUCTURE plot of European-American (EA), African American (AA), Thai, Chinese (Asian), Jewish-Israeli, and Ethiopian Jewish (EJ) samples when $K=4$. Each vertical line represents an individual with ancestry components shown as different colors.

infer proportions of world-wide ancestry in a highly migratory sample such as Jews with grandparents born on all continents.

$\mathrm{Xu}$ and Jin [41] demonstrated both European and Asian contributions to the Uyghur population of Western China when STRUCTURE and PCA were used to analyze European, East Asian and Uyghur sample data. They noted, however, that when world-wide HGDP-CEPH samples including Uyghur were analyzed in other studies, there appeared to be three parental populations for Uyghur: European, East Asian, and Central Asian [42,43]. Consistent with our results, this is an example of the value of including additional reference samples or parental populations in detecting subtle substructure and admixture in the populations to which they contributed.

Our finding that there is little Sub-Saharan African admixture in North African Jewish populations (average percent African ancestry component based on STRUCTURE results for samples with four grandparents from a given country: Libya (0.07), Morocco (0.03), Tunisia (0.09), Egypt (0.03)) are consistent with findings from the Behar mtDNA study, which detected low rates of Sub-
Saharan African, and no North African maternal contribution to Moroccan, Tunisian, and Libyan Jewish populations. Our findings of significant Sub-Saharan African ancestry in Ethiopian Jews (0.55) in contrast to Yemenite Jews (0.03) were also consistent with mtDNA [26] and Ychromosomal [23] studies. Our analyses based on autosomal data cannot rule out local North African contribution to the North African Jewish populations studied here. However, given the finding that non-Jewish North African populations have approximately 25\% [44] SubSaharan African mtDNA contribution, we would have expected a significant Sub-Saharan component in the North African Jewish populations that we included. That we did not find such a component may reflect relative reproductive isolation among the North African Jewish communities and their host populations.

Our results on population substructure reflect the influence of numerous factors, including the recent founding of Ashkenazi vs. non-Ashkenazi Jewry, gene flow between these groups and between Jewish and nonJewish populations, a highly complex migration history, and the characteristics and limitations of the marker set

Table 1: Two-sided two sample t-tests via Monte-Carlo permutation with 10000 reps showed significant differences between AJ and NAJ for Northern and Southern assignment values but not for Asian or African assignment values.

permutation of individual AJ and NAJ assignment values - 10000 reps

African

Asian

Northern

Southern

\begin{tabular}{lllll} 
mean difference & 0.0111 & 0.0027 & 0.4148 & 0.4069 \\
\hline$p$-value & 0.1182 & 0.6387 & $<2.2 \mathrm{e}-16$ \\
\hline
\end{tabular}




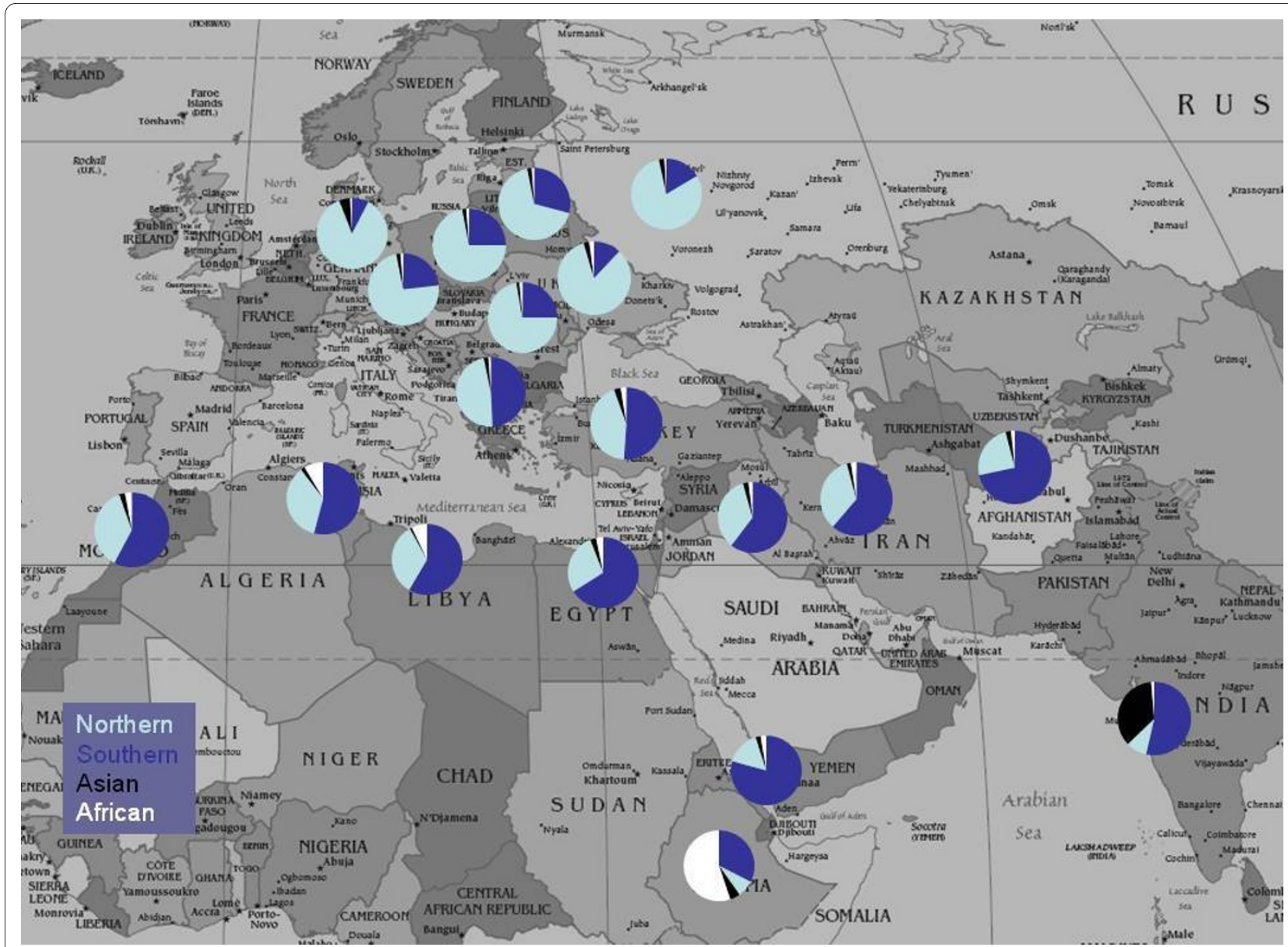

Figure 2 Ancestry proportions by grandparental country of origin. For individuals from the Jewish-Israeli sample with four grandparents from the same country and for the Ethiopian-Jewish sample, proportions of ancestry for individuals from a given geographic point are shown as segments of each pie chart.

used in this study. The documented history of the Eurasian and North African Jewish populations indicates that the Diaspora did not radiate outward geographically from the Middle East in a simple starburst pattern -rather, Ashkenazi and non-Ashkenazi Jews migrated repeatedly in and out of Europe, Africa, the Middle East, and Central, South, and East Asia. Cultural differences, once established, may have promoted differentiation between the Ashkenazi and non-Ashkenazi Jews in spite of their repeated geographic overlap. High variance of Northern and Southern components within a subset of individuals with the same grandparental country of birth even for those with large sample size (table 2) likely reflects recent admixture [41] as well as the small set of markers.

Although within each group there is a high degree of variability among individual assignment values, geographic patterns are seen in the average North/South percent assignment values between groups as defined by $\mathrm{AJ}$ or NAJ, grandparental world region of birth, or grandpar- ental country of birth. For AJ and NAJ these differences were found to be statistically significant (table 1) (significance was not tested for differences between regions or grandparental country of birth because sample sizes varied greatly). Thus, even based on data from a small marker set, AJ are not a homogeneous population. For non-Ashkenazi Jews, the small measured Sub-Saharan and small inferred Northern African contribution in all Jewish communities of African origin other than Ethiopian may be due to a greater degree of endogamy within those communities.

After demonstrating the feasibility of distinguishing Ashkenazi Jews from non-Jewish Europeans using autosomal SNPs, Need et al [10] analyzed these samples in conjunction with a number of Middle-Eastern populations and concluded, in contrast to Behar et al [6], that the differentiation of Ashkenazi Jews from non-Jewish Europeans was due to their Middle-Eastern ancestry rather than a bottleneck event because the Ashkenazi Jewish sample had high heterozygosity. Although we 
Table 2: average, variance, and standard deviation of percent assignment value per cluster when $K=4$

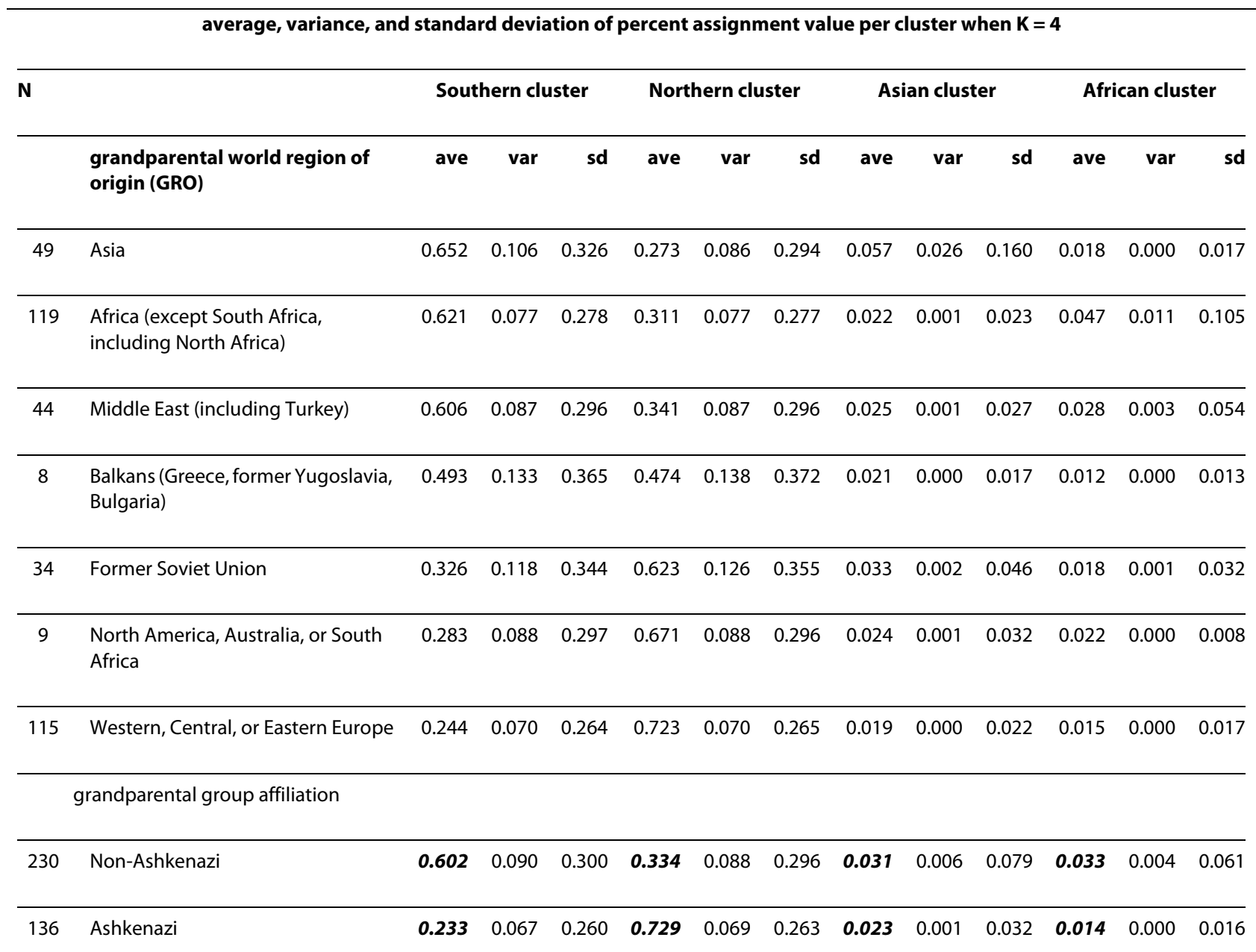

grandparental country of birth (GCB)

\begin{tabular}{|c|c|c|c|c|c|c|c|c|c|c|c|c|c|}
\hline 46 & Yemen & 0.793 & 0.051 & 0.226 & 0.157 & 0.049 & 0.220 & 0.023 & 0.001 & 0.031 & 0.026 & 0.003 & 0.052 \\
\hline 5 & Afghanistan/Uzbekistan & 0.716 & 0.079 & 0.281 & 0.243 & 0.075 & 0.274 & 0.023 & 0.001 & 0.023 & 0.017 & 0.000 & 0.008 \\
\hline 4 & Egypt & 0.661 & 0.049 & 0.221 & 0.280 & 0.053 & 0.231 & 0.026 & 0.001 & 0.023 & 0.033 & 0.000 & 0.017 \\
\hline 4 & $\begin{array}{l}\text { Bulgaria (included on Fig. } 2 \text { with } \\
\text { Balkan) }\end{array}$ & 0.629 & 0.105 & 0.324 & 0.329 & 0.109 & 0.330 & 0.029 & 0.000 & 0.019 & 0.013 & 0.000 & 0.008 \\
\hline 13 & Iran & 0.613 & 0.119 & 0.345 & 0.345 & 0.107 & 0.327 & 0.018 & 0.001 & 0.023 & 0.024 & 0.001 & 0.031 \\
\hline 29 & Iraq & 0.603 & 0.087 & 0.295 & 0.353 & 0.085 & 0.292 & 0.025 & 0.001 & 0.025 & 0.019 & 0.000 & 0.022 \\
\hline 14 & Libya & 0.585 & 0.055 & 0.234 & 0.334 & 0.071 & 0.266 & 0.010 & 0.000 & 0.005 & 0.071 & 0.012 & 0.109 \\
\hline 47 & Morocco & 0.578 & 0.089 & 0.298 & 0.368 & 0.089 & 0.298 & 0.024 & 0.001 & 0.022 & 0.030 & 0.002 & 0.039 \\
\hline 10 & Tunisia & 0.541 & 0.039 & 0.198 & 0.355 & 0.043 & 0.208 & 0.018 & 0.000 & 0.008 & 0.086 & 0.007 & 0.083 \\
\hline 6 & India & 0.537 & 0.158 & 0.398 & 0.091 & 0.015 & 0.121 & 0.357 & 0.119 & 0.346 & 0.014 & 0.000 & 0.008 \\
\hline
\end{tabular}


Table 2: average, variance, and standard deviation of percent assignment value per cluster when $K=4$ (Continued)

\begin{tabular}{llllllllllllll}
\hline 5 & Turkey & 0.511 & 0.086 & 0.293 & 0.434 & 0.105 & 0.324 & 0.030 & 0.001 & 0.024 & 0.025 & 0.000 & 0.017 \\
\hline 42 & Ethiopian Jews & 0.325 & 0.074 & 0.272 & 0.078 & 0.008 & 0.089 & 0.046 & 0.004 & 0.064 & 0.552 & 0.097 & 0.312 \\
\hline 7 & Belorus/Lithuania/Latvia/Ukraine & 0.291 & 0.145 & 0.381 & 0.678 & 0.145 & 0.381 & 0.019 & 0.000 & 0.014 & 0.012 & 0.000 & 0.009 \\
\hline 31 & Poland & 0.250 & 0.090 & 0.299 & 0.719 & 0.090 & 0.300 & 0.018 & 0.000 & 0.020 & 0.013 & 0.000 & 0.010 \\
\hline 18 & Romania & & & & & & & & & & & \\
\hline 6 & Czech/Hungary/Austria & 0.249 & 0.058 & 0.240 & 0.724 & 0.058 & 0.240 & 0.014 & 0.000 & 0.012 & 0.014 & 0.000 & 0.014 \\
\hline 7 & Russia & 0.231 & 0.056 & 0.237 & 0.737 & 0.056 & 0.237 & 0.018 & 0.000 & 0.016 & 0.014 & 0.000 & 0.005 \\
\hline 6 & Ukraine & 0.165 & 0.077 & 0.277 & 0.801 & 0.085 & 0.292 & 0.025 & 0.000 & 0.018 & 0.010 & 0.000 & 0.008 \\
\hline 6 & Germany & 0.120 & 0.003 & 0.055 & 0.834 & 0.005 & 0.073 & 0.024 & 0.001 & 0.032 & 0.021 & 0.000 & 0.015 \\
\hline
\end{tabular}

Shown, for a given subset of individuals, are average, variance, and s.d. of assignment values from STRUCTURE results when $\mathrm{K}=4$. Differences in assignment values for Northern, Southern, Asian, and African clusters (italicized and in bold) were found to be significant between NonAshkenazi and Ashkenazi Jews based on 10000 permutations of assignment values. Variance of Northern and Southern assignment values was high within a subset based on grandparental country of birth (GCB), with the exception of Ukraine and Germany (italicized). For GCB, in four instances, individuals were combined into a subset when GCBs were adjoining geographically and had a history of border shifts and periods of unification or division (ex: Czech/Hungary/Austria), such that the town or city in which a grandparent was born might currently lie in one of the neighboring countries rather than the stated GCB.

agree that the Middle-Eastern ancestry of Ashkenazi Jews is demonstrated by the PCA analyses in Need et al [10], we are less confident in the validity of their conclusion that no bottleneck occurred. As we demonstrate, there is wide genetic variation among Ashkenazi Jewish sub-populations both between and within grandparental country of birth. Elevated heterozygosity may reflect either recent admixture or the combining of multiple Ashkenazi populations by Need et al into one sample for analysis.

Our autosomal data from a small number of Jews with grandparents from India $(\mathrm{N}=6)$ show significant Asian admixture (0.36) while also showing the highest ratio of Southern/Northern contribution. Of all non-Ashkenazi Jewish populations, Jews of Yemenite, Egyptian, and Central Asian descent have the largest Southern component $(0.79,0.73$, and 0.72 , respectively). These results concur with both molecular and historical evidence. Behar et al [6] studied a large mtDNA dataset of non-Ashkenazi Jews and their previous dataset of Ashkenazi Jews and detected a small amount of Sub-Saharan African and no local North African maternal contribution to Moroccan, Tunisian, and Libyan Jewish populations. Sub-Saharan African-specific mtDNA lineages were found at high frequencies in Ethiopian and moderate frequencies in Yemenite Jews. Local South Asian mtDNA contribution was detected in two Indian Jewish populations. Historically, Yemenite, Egyptian, and Central Asian are some of the oldest Jewish communities, established after the first Jewish exile from Jerusalem [45-48]. Jews settled in India as early as the $7^{\text {th }}$ century CE, possibly from Iran or Yemen and incorporated local residents as well as slaves into the population [48].

\section{Theoretical implications}

The large Jewish-Israeli sample in this study was collected as part of a greater study on health-related phenotypes; it contained 526 individuals with grandparents from a broad geographic range: Northern and Southern Europe, Russia, North Africa, Ethiopia, the Middle East, Central Asia, and India. While it is not surprising that this sample (based on historical accounts, mtDNA and Y-chromosome studies, and geographic range) has components of all three major continental populations that vary based on recent ancestral origin, these differences in ancestry were not detected without the addition of putative parental population or reference samples in STRUCTURE analysis. The significance of the resultant ancestry components could not have been evaluated in the absence of self-reported information on family history and identification. Such detail is not always available for population samples; however it proved to be highly valuable in this 
Delta values for each population pair

\begin{tabular}{|c|c|c|c|c|c|c|c|c|c|c|c|c|c|c|c|}
\hline & Locus & EJ/ANAJ & EJ/NAJ & EJ/AA & EJ/EA & AJ/ANAJ & AJ/NAJ & AJ/AA & $A J / E A$ & ANAJ/NAJ & ANAJ/AA & ANAJ/EA & NAJ/AA & NAJ/EA & AA/EA \\
\hline & CSF1PO & 0.09 & 0.10 & 0.18 & 0.18 & 0.13 & 0.05 & 0.16 & 0.11 & 0.09 & 0.22 & 0.19 & 0.17 & 0.10 & 0.15 \\
\hline & D2S1338 & 0.30 & 0.25 & 0.32 & 0.37 & 0.10 & 0.18 & 0.26 & 0.11 & 0.14 & 0.24 & 0.12 & 0.29 & 0.14 & 0.28 \\
\hline & D3S1358 & 0.14 & 0.10 & 0.18 & 0.18 & 0.17 & 0.17 & 0.16 & 0.11 & 0.12 & 0.12 & 0.18 & 0.20 & 0.14 & 0.21 \\
\hline & D5S818 & 0.22 & 0.11 & 0.21 & 0.13 & 0.15 & 0.12 & 0.18 & 0.12 & 0.21 & 0.20 & 0.24 & 0.17 & 0.14 & 0.18 \\
\hline & D7S820 & 0.16 & 0.09 & 0.16 & 0.09 & 0.11 & 0.05 & 0.18 & 0.08 & 0.08 & 0.26 & 0.14 & 0.19 & 0.07 & 0.13 \\
\hline & D8S1179 & 0.19 & 0.14 & 0.30 & 0.28 & 0.10 & 0.16 & 0.27 & 0.16 & 0.13 & 0.25 & 0.10 & 0.30 & 0.18 & 0.30 \\
\hline & D13S317 & 0.23 & 0.12 & 0.18 & 0.19 & 0.05 & 0.17 & 0.33 & 0.11 & 0.13 & 0.33 & 0.10 & 0.22 & 0.08 & 0.22 \\
\hline & D16S539 & 0.18 & 0.11 & 0.22 & 0.12 & 0.07 & 0.11 & 0.19 & 0.07 & 0.17 & 0.22 & 0.10 & 0.15 & 0.11 & 0.23 \\
\hline & D18S51 & 0.28 & 0.28 & 0.29 & 0.22 & 0.12 & 0.18 & 0.40 & 0.19 & 0.15 & 0.40 & 0.19 & 0.43 & 0.20 & 0.24 \\
\hline & D19S433 & 0.21 & 0.15 & 0.25 & 0.22 & 0.12 & 0.14 & 0.24 & 0.07 & 0.15 & 0.25 & 0.10 & 0.17 & 0.13 & 0.25 \\
\hline$\infty \stackrel{\stackrel{\llcorner}{N}}{\stackrel{n}{\sim}}$ & D21S11 & 0.30 & 0.26 & 0.34 & 0.41 & 0.22 & 0.13 & 0.28 & 0.23 & 0.16 & 0.26 & 0.25 & 0.29 & 0.21 & 0.21 \\
\hline 흥 & FGA & 0.24 & 0.19 & 0.20 & 0.20 & 0.13 & 0.13 & 0.27 & 0.10 & 0.19 & 0.35 & 0.17 & 0.20 & 0.15 & 0.27 \\
\hline 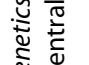 & TH01 & 0.26 & 0.19 & 0.19 & 0.20 & 0.05 & 0.19 & 0.36 & 0.13 & 0.17 & 0.33 & 0.10 & 0.29 & 0.13 & 0.24 \\
\hline$\sum_{\infty}^{\cup} \stackrel{\mathscr{\omega}}{\varrho}$ & TPOX & 0.24 & 0.23 & 0.22 & 0.24 & 0.07 & 0.05 & 0.20 & 0.08 & 0.05 & 0.25 & 0.08 & 0.23 & 0.06 & 0.28 \\
\hline 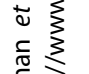 & vWA & 0.24 & 0.16 & 0.20 & 0.20 & 0.10 & 0.17 & 0.35 & 0.12 & 0.14 & 0.38 & 0.11 & 0.27 & 0.10 & 0.36 \\
\hline
\end{tabular}


Table 3: Delta values for each population pair for each marker (Continued)

\begin{tabular}{|c|c|c|c|c|c|c|c|c|c|c|c|c|c|c|c|}
\hline D17S799 & & 0.35 & 0.42 & 0.24 & 0.45 & 0.14 & 0.12 & 0.52 & 0.19 & 0.10 & 0.41 & 0.21 & 0.49 & 0.12 & 0.51 \\
\hline D8S272 & $\mathrm{N} / \mathrm{A}$ & & N/A & N/A & $\mathrm{N} / \mathrm{A}$ & 0.09 & 0.18 & 0.34 & 0.10 & 0.17 & 0.35 & 0.17 & 0.46 & 0.18 & 0.34 \\
\hline D7S640 & & 0.35 & 0.36 & 0.42 & 0.41 & 0.15 & 0.15 & 0.40 & 0.17 & 0.16 & 0.43 & 0.20 & 0.32 & 0.19 & 0.35 \\
\hline D8S1827 & & 0.21 & 0.21 & 0.36 & 0.20 & 0.09 & 0.09 & 0.42 & 0.11 & 0.03 & 0.50 & 0.18 & 0.50 & 0.17 & 0.38 \\
\hline D22S274 & & 0.16 & 0.15 & 0.19 & 0.24 & 0.15 & 0.09 & 0.16 & 0.12 & 0.14 & 0.13 & 0.18 & 0.14 & 0.16 & 0.20 \\
\hline D5S407 & & 0.20 & 0.18 & 0.27 & 0.31 & 0.08 & 0.14 & 0.34 & 0.18 & 0.17 & 0.35 & 0.20 & 0.26 & 0.18 & 0.32 \\
\hline D2S162 & & 0.27 & 0.26 & 0.34 & 0.33 & 0.16 & 0.17 & 0.37 & 0.12 & 0.19 & 0.40 & 0.22 & 0.30 & 0.21 & 0.46 \\
\hline D10S197 & & 0.34 & 0.32 & 0.31 & 0.26 & 0.13 & 0.22 & 0.26 & 0.15 & 0.11 & 0.30 & 0.11 & 0.31 & 0.09 & 0.23 \\
\hline D11S935 & & 0.23 & 0.18 & 0.44 & 0.25 & 0.07 & 0.12 & 0.65 & 0.18 & 0.07 & 0.64 & 0.16 & 0.59 & 0.14 & 0.58 \\
\hline D9S175 & & 0.33 & 0.30 & 0.50 & 0.34 & 0.17 & 0.13 & 0.46 & 0.13 & 0.17 & 0.54 & 0.19 & 0.49 & 0.12 & 0.49 \\
\hline D5S410 & & 0.21 & 0.13 & 0.24 & 0.27 & 0.10 & 0.10 & 0.43 & 0.16 & 0.12 & 0.42 & 0.15 & 0.34 & 0.22 & 0.44 \\
\hline D7S2469 & & 0.29 & 0.23 & 0.30 & 0.29 & 0.15 & 0.10 & 0.31 & 0.13 & 0.12 & 0.31 & 0.15 & 0.32 & 0.14 & 0.33 \\
\hline D16S3017 & & 0.28 & 0.23 & 0.21 & 0.30 & 0.18 & 0.13 & 0.27 & 0.08 & 0.09 & 0.32 & 0.10 & 0.28 & 0.09 & 0.30 \\
\hline D10S1786 & & 0.31 & 0.24 & 0.27 & 0.28 & 0.09 & 0.12 & 0.49 & 0.05 & 0.10 & 0.54 & 0.09 & 0.49 & 0.13 & 0.48 \\
\hline D15S1002 & & 0.23 & 0.12 & 0.38 & 0.21 & 0.13 & 0.13 & 0.53 & 0.12 & 0.14 & 0.51 & 0.14 & 0.43 & 0.12 & 0.48 \\
\hline D6S1610 & & 0.26 & 0.19 & 0.15 & 0.18 & 0.12 & 0.13 & 0.28 & 0.16 & 0.13 & 0.31 & 0.24 & 0.24 & 0.16 & 0.25 \\
\hline D1S2628 & & 0.32 & 0.27 & 0.28 & 0.35 & 0.07 & 0.10 & 0.46 & 0.08 & 0.13 & 0.49 & 0.06 & 0.39 & 0.11 & 0.45 \\
\hline AVERAGE & & 0.25 & 0.20 & 0.27 & 0.25 & 0.12 & 0.13 & 0.33 & 0.13 & 0.13 & 0.34 & 0.15 & 0.31 & 0.14 & 0.32 \\
\hline
\end{tabular}


case. Others have shown that the ability to detect population substructure is dependant, in part, on sample size or the inclusion of reference populations $[41,49,50]$. For a sample in which populations have diverged recently or have low levels of genetic differentiation (such as Ashkenazi and non-Ashkenazi Jews), the ability to detect substructure increases with the amount of data available, with the total data being a result of information derived both from the number and informativeness of samples as well as the number and informativeness of markers [49,51].

This issue has great practical relevance for the substructure testing phase of association mapping studies in which cases and controls are from the same self-identified population group, particularly when increasing the number of AIMs is not an immediate option. Numerous other genetic studies have shown that Jewish populations, while sharing ancient Middle-Eastern ancestry, have practiced exogamy or incorporated members of local populations to some extent $[3-6,8,11,20,22,23]$. It is this gene flow from host populations combined with genetic drift and possible local selection pressures, that have led to detectable substructure among Jewish populations, perhaps more so than would be expected based solely on time since population divergence.

\section{Historical Implications}

In contrast to Seldin et al [25], we showed varying Northern and Southern components among Ashkenazi Jewish populations. Non-Jewish population samples in the Seldin et al study were European or European American in origin, while our study included African-American and Asian samples as well as European Americans. In addition, the Jewish sample in Seldin et al included only three Sephardic (based on their nomenclature) Jews, too few to provide reliable information about this population. The Kopelman et al study [28], in addition to European Jews and non-Jews, included two North African Jewish populations as well as Middle Eastern non-Jewish populations. Our study included a large number of non-Ashkenazi Jews including those from North Africa, the Near East, Ethiopia, and Central and South Asia. We believe that our study demonstrates the effect of relative population genetic differences and total information from markers and individuals on clustering patterns. As we have described previously, our STR panel was chosen specifically for its high information content [50]. Although the major consideration in marker selection for this panel was the ability to differentiate between major American populations, we previously demonstrated that the same panel was, somewhat unexpectedly, also very useful at distinguishing different Asian populations [52].

The migratory history and origins of Ashkenazi Jews are less clear than those of non-Ashkenazi Jews. During the early Middle Ages in Europe, Jews lived in close proximity with their non-Jewish neighbors in small villages with constant interaction. Intermarriage, although periodically outlawed by host-country governments, occurred with some regularity [53]. In addition, Jewish Europe was never solely inhabited by Ashkenazi Jews. Some Jews expelled from Spain during the inquisition settled in part of the Ottoman Empire, which includes the Balkans (present-day Turkey, Bulgaria, Greece, Bosnia, and Serbia), while others went to Italy, Holland, and France [54]. In fact, all subjects in this study who identified their grandparents as having come from Balkan countries also identified themselves as non-Ashkenazi and those with two grandparents from Balkan countries identified the parent on that side as non-Ashkenazi.

We believe that the apparent Southern genetic component of those of European descent (Jewish or not), as well as that seen in Jews, is actually originally Middle Eastern in origin. This is consistent to various degrees with previous results from y-chromosomal [3,8], mtDNA [3,5,21] and autosomal evidence $[25,26]$ as well as historical evidence. The large Northern component in all Ashkenazi populations included in this study indicates significant local contribution to these populations, which either occurred early in their histories (German and Ukraine) or in small increments over time (other Ashkenazi populations as evidenced by high variance of Northern/Southern components). Among non-Ashkenazi Jewish populations sampled, although all have exhibited porous membership, Ethiopian and Indian Jewish communities have particularly significant local contributions to their gene pools.

The high variance for percent Southern and Northern components for group affiliation, region of birth, and grandparental country of birth, indicate that admixture and migratory events are recent [41]. This reflects both the complex migration histories of Jewish populations and the limitations of the marker set used here, including the possibility of homoplasious alleles interfering with accurate ancestral population assignment. Despite small sample sizes, the variance was small for individuals with four German $(\mathrm{N}=6)$ (Southern $\sigma^{2}=0.005$, Northern $\sigma^{2}=$ $0.005)$ or four Ukrainian $(\mathrm{N}=6)$ (Southern $\sigma^{2}=0.003$, Northern $\left.\sigma^{2}=0.005\right)$ grandparents, which may indicate that admixture events in these populations are older than those of other Jewish populations in our study.

\section{Conclusions}

Our results reinforce conclusions of previous characterizations of Jewish samples based on uniparentally-inherited segments of the genome. Jewish populations are not necessarily genetically homogeneous, either as a whole, within the Ashkenazi or non-Ashkenazi affiliations, or within a continent. Geographic gradients of genetic het- 
erogeneity such as that observed here within what is seemingly one population have been shown empirically to confound association studies [26], but in the absence of a very large AIM panel, are correctable when information such as grandparental country or region of birth is used to create subsets of matched cases and controls $[55,56]$.

Although clustering programs such as STRUCTURE are designed to assign proportions of ancestry to individuals without the necessity of including parental population information, when our mixed Jewish sample was analyzed without the EA, AA, Thai, and Chinese samples, the substructure within Jews was not apparent. While it is true that Jewish samples would be shown to contain substructure if analyzed with thousands of SNP markers or hundreds of STR markers, it is unlikely that subtleties contributed by Asian and African admixture would be detected without inclusion of world-wide reference samples. For example, Kopelman et al [28] used data from 678 STRs for four Jewish populations (Moroccan, Tunisian, Turkish, and Ashkenazi) combined with that of Middle Eastern and European populations and it was found that the Jewish populations had ancestry to varying degrees from both European and Middle Eastern populations. They do not find information regarding Asian or Sub-Saharan African admixture because that is not possible without the inclusion of samples from those regions. When they used STRUCTURE to analyze their Jewish samples, alone, the best fit for the data was two parental populations.

We demonstrated empirically, the effect of reference population inclusion on the ability to cluster individuals in an admixed population. Studies commonly control for population stratification by genotyping subjects, only, with a panel of non-coding markers. However, when cases and controls have been matched (non-genetically) for ancestry and no other populations that could potentially contribute to admixture are included in the analysis, any existing substructure is unlikely to be detected. We suggest that samples of reference or proxy parental populations be included in the substructure testing phase of case control association studies when the participants are sampled from potentially admixed populations such as populations residing in or originating from major human migratory pathways, urban populations, or American populations.

The total number of markers used in this study is quite small in comparison to many other available studies, but due to higher mutation rates and number of alleles per locus STRs provide much more information, on average, than SNPs for population assignment and population stratification [19]. The high variation and high mutation rates for STRs may backfire, however, when attempting to distinguish between populations that have diverged long ago, as homoplasic alleles can accumulate under those circumstances. We found previously [52] that the tetra- nucleotide CODIS loci were not useful in distinguishing between AA and EA populations while they were highly informative when distinguishing among more recentlydiverged Asian minority populations [57]. This marker set may be more useful for detecting recent admixture or founding events, such as those which formed the Jewish populations in question, here.

\section{Methods \\ Populations and Sampling}

A total of 780 subjects were selected for inclusion in this study: mixed Jewish $(\mathrm{N}=526)$ (the central sample of interest for which it was our goal to detect population structure), Ethiopian Jewish (EJ, $\mathrm{N}=42)$, Thai $(\mathrm{N}=45)$, Chinese $(\mathrm{N}=29)$, African American (AA, $\mathrm{N}=54)$, and European American (EA, $N=91$ ). For some analyses, the mixed Jewish sample, collected in Israel, was divided into subsets based on self-reported information about parents. This included individuals with two Ashkenazi parents (AJ, $N=135$ ), individuals with two non-Ashkenazi parents (NAJ, $\mathrm{N}=226$ ), and individuals with one Ashkenazi and one non-Ashkenazi parent (ANAJ, $\mathrm{N}=38$ ). These sub-samples do not add up to the total mixed Jewish sample due to missing self-report parental or grandparental information. The Asian populations in this study were collected as part of an ongoing gene mapping study. Samples of individuals self-identified as being of Thai and Chinese ancestry were obtained from a blood drive in Bangkok, Thailand. The Thai and Chinese samples used in this study were selected to include only subjects for whom all four grandparents were reported to have the same self-identified ethnicity as the subject. For analyses the Thai and Chinese samples were combined into one sample labeled Asian. The dataset also included samples of unrelated AAs and EAs a subset of a sample described elsewhere and for which population group self-identifications were previously confirmed via Bayesian marker clustering [50]. Note that the EA sample was not screened to exclude AJ or NAJ subjects so it is likely to contain small numbers of them. The EJ sample was obtained from the National Laboratory for the Genetics of Israeli Populations, Sackler Faculty of Medicine, Tel Aviv University, Israel. This work was approved by the Yale University School of Medicine Human Investigation Committee HIC\#12183, New York State Psychiatric Institute Institutional Review Board protocol\#4753, Israel Board of the Ministry of Health Helsinki Committee for Genetic Trials \#920050036, and the Department of Veterans Affairs Subcommittee on Human Studies \#0008. All subjects provided informed consent as approved by the appropriate institutional review boards.

\section{Markers and Genotyping}

All samples were genotyped for thirty-two unlinked autosomal STR markers (with the exception of EJ, for which 
data are missing for D8S272). The panel is comprised of the 15 tetranucleotide repeats in the AmpF/STR Identifiler PCR Amplification kit (PE Applied Biosystems, Foster City, CA, USA) (D8S1179 [GenBank:AX412206], D21S11 [GenBank:AJ550387], D7S820 [GenBank:NC 000007], CSF1PO [GenBank:AF076965], D3S1358 [UniSTS:148226], TH01 [UniSTS:240639], D13S317 [GenBank:G09017], D16S539 [GenBank:AF249681, D2S1338 [GenBank:G08202], D19S433 [GenBank:G08036 ], vWA [UniSTS:240641], TPOX [GenBank:M25706], D18S51 [GenBank:L18333], D5S818 [GenBank:G08446 and FGA [GenBank:G3347]) and an additional 17 dinucleotide repeats (D17S799 [GenBank:Z16830], D8S272 [GenBank:Z17250], D7S640 [GenBank:Z23671], D8S1827 [GenBank:Z50970], D22S274 [GenBank:Z16730, D5S407 [GenBank:Z16723], D2S162 [GenBank:Z17035], D10S197 [GenBank:Z16611], D11S935 [GenBank:Z17148], D9S175 [GenBank:Z17021], D5S410 [GenBank:Z16825], D7S2469 [GenBank:Z53000], D16S3017 [GenBank:Z52036], D10S1786 [GenBank:Z51854], D15S1002 [GenBank:ZZ53249], D6S1610 [GenBank:Z253131], and D1S2628 [GenBank:Z52173]). The amelogenin locus, included in the AmpF/STR Identifiler PCR Amplification kit for sex identification, was not included in any analyses. All STR markers were analyzed on an ABI PRISM 3100 semiautomated capillary fluorescence sequencer. Data were scored using Genemapper (ABI). We previously used this marker panel (with the addition of D1S196, D2S319, D7S657, D12S352, D14S68, which were not used here either because they were replaced with D7S2469 and D1S2628 or because of a large number of failed genotypes) to determine and statistically correct for ancestry in case-control studies and genome-wide linkage studies [58-61] and in population genetics studies [52].

\section{Statistical Analyses}

\section{Population Differentiation}

The program STRUCTURE 2.2 [36,37] uses Bayesian clustering of multilocus genotypes to assign individuals to populations, estimate admixture proportions for individuals, and infer the number of parental populations (K) for a sample. Because variance of STRUCTURE results increases with small sample sizes each run was repeated 5 times with all 32 STR markers in the panel. For analyses that included AA, EA, Thai, Chinese, EJ and mixed Jewish populations, the parameters used were $\mathrm{K}=2$ through $\mathrm{K}=9$ and 50,000 burn-in and 50,000 Markov chain Monte Carlo (MCMC) iterations. For analyses that included only the EA and mixed Jewish samples in the absence of all other samples, the parameters used were $\mathrm{K}$ $=2$ through $\mathrm{K}=4$ and 50,000 burn-in and 50,000 Markov chain Monte Carlo (MCMC) iterations. The self-reported population of origin was not used as additional data by STRUCTURE and the presence of admixture was assumed.

The authors of STRUCTURE recommend using the maximal value for $\ln \mathrm{P}(\mathrm{D})$ to determine the best value of $\mathrm{K}$ for the data. However, it has been observed that $\ln \mathrm{P}(\mathrm{D})$ will plateau while continuing to increase slightly as assumed $\mathrm{K}$ increases past the correct $\mathrm{K}$. Therefore, identifying the $K$ for which $\ln P(D)$ is greatest may not be sufficient to identify the correct (underlying) K. We employed StructureSum, an R script that uses the output from STRUCTURE to identify the $K$ for which $\ln P(D)$ is maximized while both $\left|\ln \mathrm{P}(\mathrm{D})_{\mathrm{K}+1}-\left(\ln \mathrm{P}(\mathrm{D})_{\mathrm{K}}-\ln \mathrm{P}(\mathrm{D})_{\mathrm{K}-1}\right)\right|$ and variance of $\ln \mathrm{P}(\mathrm{D})$ are minimized. This identifies the highest value of $K$, prior to the plateau of $\ln P(D)$ [38].

STRUCTURE runs were unsupervised, using the admixture model and correlated allele frequencies. Structure randomly assigns clusters in each run such that the correspondence between runs is non-obvious. CLUMPP software [62] takes the multiple results files and determines which clusters from different runs correspond, then averages the assignment values between runs for each individual. To account for cluster label switching between runs, we used the fullsearch option and nonweighted alignment procedure in CLUMPP version 1.1.1 to identify corresponding clusters between runs for a set of five runs with a given $\mathrm{K}$ and to produce average membership coefficients for each individual for each cluster. These average assignment values were used with the program, DISTRUCT [63], to produce graphs of STRUCTURE output.

For Jewish-Israelis with four grandparents from the same country, for $K=4$, individual assignment values produced by CLUMPP were averaged to arrive at values for Northern, Southern, Asian, and African ancestral components for the Jewish population of that geographic location. This was also done for AJ, NAJ, and ANAJ.

A two Sample t-test via monte-carlo permutation was used to test for significance between the individual AJ and NAJ assignment values with 10,000 samples simulated when $\mathrm{H}_{0}$ (no significant difference between average assignment values for two populations) is true. The t-test value of the observed data was then compared to that of the simulated data to obtain a p-value for mean differences in assignment values between $\mathrm{AJ}$ and NAJ.

\section{Hardy Weinberg Equilibrium (HWE)}

Tests for deviation from Hardy-Weinberg equilibrium expectations were conducted using GENEPOP 4.0 [64] globally for all loci using sub-option 5 , the exact test for HWE in which $\mathrm{H}_{1}=$ heterozygote excess based on a Markov chain method. The parameters used were 5000 dememorizations, 1000 batches, and 5000 iterations per batch. The parameter values were increased from defaults 
until the observed standard error for p-values was less than 0.01. For the mixed Jewish sample this was performed for the sample as a whole, as well as for the AJ, NAJ, and ANAJ subsets. We used an exact test for multiallelic markers because Chi-squared tests are inappropriate for such analyses [65].

\section{Marker Information Content}

Markers were evaluated for delta $(\delta)$ [66], a measure of marker information content, reflecting the ability of a marker to differentiate statistically between populations.

We have confirmed that this is a relevant measure for the markers we employed herein [50]. To arrive at $\delta$, the absolute values of allelewise frequency differences between two populations are added and this sum is divided in half, i.e., $\delta=1 / 2 \sum_{i=1}^{L}\left|p_{i}^{A}-p_{i}^{B}\right|$ where $p_{i}^{A}$ and $p_{i}^{B}$ are the allele frequencies for the $i^{\text {th }}$ allele in populations $\mathrm{A}$ and $\mathrm{B}$. The more effective the marker is at differentiating between populations, the higher the value for $\delta$ [50].

\section{Authors' contributions}

$J B L$ designed the study, carried out statistical analyses and drafted the manuscript. DH participated in project coordination, sample collection, and the writing of the manuscript. AS and AM participated in sample collection in Thailand. HRK carried out sample collection in the United States. RTM participated in project coordination and sample collection. EA and BS participated in project coordination and sample collection in Israel. JG participated in study design and supervision, project coordination, sample collection, and the writing of the manuscript. All authors read and approved the final manuscript.

\section{Acknowledgements}

We appreciate receiving helpful comments from Dr Jonathan Pritchard. Greg Kay and Ann Marie Lacobelle provided excellent technical assistance. This work was supported in part by the National Institutes of Health [grant numbers R01 DA12849, R01 DA12690, K24 DA15105, K24 AA13736] and the National Institutes of Health/National Institute on Drug Abuse/Fogarty International Center [Thai-US Drug Dependence Genetics Research Training Grant D43-TW06166] $\mathrm{DH}$ is supported by the National Institutes of Health [grant number K05AA014223] and the New York State Psychiatric Institute. Support for the collection of the Israel data came from the National Institutes of Health [grant number R01AA013654] to DH. (Note that R01AA013654 is a study of alcohol-related phenotypes and a broad array of traits that may be related to alcohol consumption, and that the present study was conducted to prepare for genetic association analyses of these phenotypes and traits). AM was supported in part by the Thailand Research Fund. JBL is supported in part by a National Institutes of Health/National Institute on Drug Abuse Ruth L. Kirschstein National Research Service Award for Individual Predoctoral Fellows [grant number FDA019761A], a National Science Foundation Doctoral Dissertation Research Improvement Grant [grant number 0622348], and a Wenner Gren Foundation for Anthropological Research Dissertation Fieldwork Grant.

\section{Author Details}

'Department of Psychiatry, Yale University School of Medicine, New Haven, CT, USA, 2VA Connecticut Healthcare System, West Haven Campus, West Haven, CT, USA, ${ }^{3}$ Department of Psychiatry, Columbia University College of Physicians and Surgeons, NY, USA, ${ }^{4}$ Departments of Psychiatry and Genetics and Developmental Biology, University of Connecticut School of Medicine, Farmington, CT, USA, ${ }^{5}$ Chulalongkorn Faculty of Medicine, Bangkok, Thailand, ${ }^{6}$ Sackler Faculty of Medicine, Tel Aviv University, Tel Aviv, Israel, ${ }^{7}$ New York State Psychiatric Institute, NY, USA, ${ }^{8}$ Dept Epidemiology, Mailman School of Public Health, Columbia University, NY, USA, ${ }^{9}$ Department of Genetics, Yale University School of Medicine, New Haven, CT, USA and ${ }^{10}$ Department of Neurobiology, Yale University School of Medicine, New Haven, CT, USA

Received: 5 January 2010 Accepted: 14 June 2010

Published: 14 June 2010

\section{References}

1. Adams SM, Bosch E, Balaresque PL, Ballereau SJ, Lee AC, Arroyo E, López Parra AM, Aler M, Grifo MS, Brion M, Carracedo A, Lavinha J, MartínezJarreta B, Quintana-Murci L, Picornell A, Ramon M, Skorecki K, Behar DM, Calafell $F$, Jobling MA: The genetic legacy of religious diversity and intolerance: paternal lineages of Christians, Jews, and Muslims in the Iberian Peninsula. Am J Hum Genet 2008, 83:725-736.

2. Bar-Shira A, Hutter C, Giladi N, Zabetian C, Orr-Urtreger A: Ashkenazi Parkinson's disease patients with the LRRK2 G2019 S mutation share a common founder dating from the second to fifth centuries. neurogenetics 2009, 10:355-358.

3. Behar D, Garrigan D, Kaplan ME, Mobasher Z, Rosengarten D, Karafet TM, Quintana-Murci L, Ostrer H, Skorecki K, Hammer MF: Contrasting patterns of $Y$ chromosome variation in Ashkenazi Jewish and host non-Jewish European populations. Human Genetics 2004, 114:354-365.

4. Behar DM, Hammer MF, Garrigan D, Villems R, Bonne-Tamir B, Richards M, Gurwitz D, Rosengarten D, Kaplan M, Della Pergola S, Quintana-Murci L, Skorecki K: MtDNA evidence for a genetic bottleneck in the early history of the Ashkenazi Jewish population. Eur J Hum Genet 2004 12:355-364.

5. Behar DM, Metspalu E, Kivisild T, Achilli A, Hadid Y, Tzur S, Pereira L, Amorim A, Quintana-Murci L, Majamaa K, Herrnstadt C, Howell N, Balanovsky O, Kutuev I, Pshenichnov A, Gurwitz D, Bonne-Tamir B, Torroni A, Villems R, Skorecki K: The matrilineal ancestry of Ashkenazi Jewry: portrait of a recent founder event. Am J Hum Genet 2006, 78:487-497.

6. Behar DM, Metspalu E, Kivisild T, Rosset S, Tzur S, Hadid Y, Yudkovsky G, Rosengarten D, Pereira L, Amorim A, Kutuev I, Gurwitz D, Bonne-Tamir B, Villems R, Skorecki K: Counting the founders: the matrilineal genetic ancestry of the Jewish Diaspora. PLOS ONE 2008, 3:e2062.

7. Benedek G, Brautbar C, Vardi P, Sharon N, Weintrob N, Zung A, Israel S: Effect of polymorphism in insulin locus and HLA on type 1 diabetes in four ethnic groups in Israel. Tissue Antigens 2009, 73:33-38.

8. Hammer MF, Redd AJ, Wood ET, Bonner MR, Jarjanazi H, Karafet T, Santachiara-Benerecetti S, Oppenheim A, Jobling MA, Jenkins T, Ostrer H, Bonne-Tamir B: Jewish and Middle Eastern non-Jewish populations share a common pool of Y-chromosome biallelic haplotypes. Proc Nat/ Acad Sci USA 2000, 97:6769-74

9. Mai PL, Chatterjee N, Hartge P, Tucker M, Brody L, Struewing JP, Wacholder S: Potential Excess Mortality in BRCA1/2 Mutation Carriers beyond Breast, Ovarian, Prostate, and Pancreatic Cancers, and Melanoma. PLOS ONE 2009, 4:e4812.

10. Need A, Kasperaviciute D, Cirulli E, Goldstein D: A genome-wide genetic signature of Jewish ancestry perfectly separates individuals with and without full Jewish ancestry in a large random sample of European Americans. Genome Biology 2009, 10:R7.

11. Thomas MG, Weale ME, Jones AL, Richards M, Smith A, Redhead N, Torroni A, Scozzari R, Gratrix F, Tarekegn A, Wilson JF, Capelli C, Bradman N, Goldstein DB: Founding mothers of Jewish communities: geographically separated Jewish groups were independently founded by very few female ancestors. Am J Hum Genet 2002, 70:1411-1420.

12. Garrigan D, Hammer MF: Reconstructing human origins in the genomic era. Nat Rev Genet 2006, 7:669-680.

13. Ségurel L, Martínez-Cruz B, Quintana-Murci L, Balaresque P, Georges M, Hegay T, Aldashev A, Nasyrova F, Jobling MA, Heyer E, Vitalis R: SexSpecific Genetic Structure and Social Organization in Central Asia: Insights from a Multi-Locus Study. PLoS Genet 2008, 4:e1000200. 
14. Underhill PA, Kivisild T: Use of y chromosome and mitochondrial DNA population structure in tracing human migrations. Annu Rev Genet 2007, 41:539-564

15. Xue F, Wang Y, Xu S, Zhang F, Wen B, Wu X, Lu M, Deka R, Qian J, Jin L: A spatial analysis of genetic structure of human populations in China reveals distinct difference between maternal and paternal lineages. Eur J Hum Genet 2008, 16:705-717.

16. Ma IWY, Khan NA, Kang A, Zalunardo N, Palepu A: Systematic review identified suboptimal reporting and use of race/ethnicity in general medical journals. J Clin Epidemiol 2007, 60:572-578.

17. Payne PW, Royal C: The Role of Genetic and Sociopolitical Definitions of Racein Clinical Trials. J Am Acad Orthop Surg 2007, 15:S100-104.

18. Shanawani H, Dame L, Schwartz DA, Cook-Deegan R: Non-reporting and inconsistent reporting of race and ethnicity in articles that claim associations among genotype, outcome, and race or ethnicity. J Med Ethics 2006, 32:724-728.

19. Waples RS, Gaggiotti O: What is a population? An empirical evaluation of some genetic methods for identifying the number of gene pools and their degree of connectivity. Mol Ecol 2006, 15:1419-1439.

20. Nebel A, Filon D, Brinkmann B, Majumder PP, Faerman M, Oppenheim A: The Y Chromosome Pool of Jews as Part of the Genetic Landscape of the Middle East. Am J Hum Genet 2001, 69:1095-1112.

21. Picornell A, Giménez P, Castro JA, Ramon MM: Mitochondrial DNA sequence variation in Jewish populations. Int J Legal Med 2006, 120:271-281.

22. Santachiara Benerecetti AS, Semino O, Passarino G, Torroni A, Brdicka R, Fellous M, Modiano G: The common, Near-Eastern origin of Ashkenazi and Sephardi Jews supported by Y-chromosome similarity. Ann Hum Genet 1993, 57:55-64.

23. Shen P, Lavi T, Kivisild T, Chou V, Sengun D, Gefel D, Shpirer I, Woolf E, Hillel J, Feldman MW, Oefner PJ: Reconstruction of patrilineages and matrilineages of Samaritans and other Israeli populations from Ychromosome and mitochondrial DNA sequence variation. Hum Mutat 2004, 24:248-260

24. Price AL, Butler J, Patterson N, Capelli C, Pascali VL, Scarnicci F, Ruiz-Linares A, Groop L, Saetta AA, Korkolopoulou P, Seligsohn U, Waliszewska A, Schirmer C, Ardlie K, Ramos A, Nemesh J, Arbeitman L, Goldstein DB, Reich $\mathrm{D}$, Hirschhorn JN: Discerning the ancestry of European Americans in genetic association studies. PLoS Genet 2008, 4:e236.

25. Seldin MF, Shigeta R, Villoslada P, Selmi C, Tuomilehto J, Silva G, Belmont JW, Klareskog L, Gregersen PK: European population substructure: clustering of northern and southern populations. PLoS Genet 2006, 2:e143.

26. Tian C, Plenge RM, Ransom M, Lee A, Villoslada P, Selmi C, Klareskog L, Pulver AE, Qi L, Gregersen PK, Seldin MF: Analysis and application of European genetic substructure using $300 \mathrm{~K}$ SNP information. PLOS Genet 2008, 4:e4.

27. Feder J, Ovadia O, Glaser B, Mishmar D: Ashkenazi Jewish mtDNA haplogroup distribution varies among distinct subpopulations: lessons of population substructure in a closed group. Eur J Hum Genet 2007, 15:498-500

28. Kopelman NM, Stone L, Wang C, Gefel D, Feldman MW, Hillel J, Rosenberg NA: Genomic microsatellites identify shared Jewish ancestry intermediate between Middle Eastern and European populations. BMC Genetics 2009, 10:80.

29. Goldberg HE: From Sephardi to Mizrahi and Back Again: Changing Meanings of "Sephardi" in Its Social Environments. Jewish Social Studies 2008, 15:165-188.

30. Rosenstein C: The Liability of Ethnicity in Israel. Social Forces 1981, 59:667-686

31. Bercovich D, Elimelech A, Yardeni T, Korem S, Zlotogora J, Gal N, Goldstein N, Vilensky B, Segev R, Avraham S, Loewenthal R, Schwartz G, Anikster Y: A mutation analysis of the phenylalanine hydroxylase (PAH) gene in the Israeli population. Ann Hum Genet 2008, 72:305-309.

32. Fidder HH, Heijmans R, Chowers Y, Bar-Meir S, Avidan B, Pena AS, Crusius JB: TNF-857 polymorphism in Israeli Jewish patients with inflammatory bowel disease. Int J Immunogenet 2006, 33:81-85.

33. Kaganovich M, Peretz A, Ritsner M, Bening Abu-Shach U, Attali B, Navon R: Is the WKL1 gene associated with schizophrenia? Am J Med Genet $B$ Neuropsychiatr Genet 2004:31-37.
34. Quint A, Lerer I, Sagi M, Abeliovich D: Mutation spectrum in Jewish cystic fibrosis patients in Israel: implication to carrier screening. Am J Med Genet A 2005, 136:246-248.

35. Listman JB, Hasin D, Kranzler HR, Frisch A, Weizman A, Aharonovich E, Malison RT, Mutirangura A, Sughondhabirom A, Gelernter J: Detection of population substructure among Jews and a north/south gradient within Ashkenazi Jews using 32 STR markers [abstract 2562]. ASHG 2008 [http://www.ashg.org/cgi-bin/2008/ashg08s].

36. Falush D, Stephens M, Pritchard JK: Inference of population structure using multilocus genotype data: linked loci and correlated allele frequencies. Genetics 2003, 164:1567-1587.

37. Pritchard JK, Stephens M, Donnelly P: Inference of population structure using multilocus genotype data. Genetics 2000, 155:945-959.

38. Rosenberg NA, Mahajan S, Ramachandran S, Zhao C, Pritchard JK, Feldman MW: Clines, clusters, and the effect of study design on the inference of human population structure. PLoS Genet 2005, 1:e70.

39. Evanno G, Regnaut S, Goudet J: Detecting the number of clusters of individuals using the software STRUCTURE: a simulation study. Mol Ecol 2005, 14:2611-2620

40. Lovell A, Moreau C, Yotova V, Xiao F, Bourgeois S, Gehl D, Bertranpetit J, Schurr E, Labuda D: Ethiopia: between Sub-Saharan Africa and western Eurasia. Ann Hum Genet 2005, 69:275-287.

41. Xu S, Jin L: A genome-wide analysis of admixture in Uyghurs and a high-density admixture map for disease-gene discovery. Am J Hum Genet 2008, 83:322-336.

42. Li JZ, Absher DM, Tang H, Southwick AM, Casto AM, Ramachandran S, Cann HM, Barsh GS, Feldman M, Cavalli-Sforza LL, Myers RM: Worldwide human relationships inferred from genome-wide patterns of variation. Science 2008, 319:1100-1104

43. Rosenberg NA, Pritchard JK, Weber JL, Cann HM, Kidd KK, Zhivotovsky LA, Feldman MW: Genetic Structure of Human Populations. Science 2002, 298:2381-2385

44. Brakez Z, Bosch E, Izaabel H, Akhayat O, Comas D, Bertranpetit J, Calafell F: Human mitochondrial DNA sequence variation in the Moroccan population of the Souss area. Ann Hum Bio/ 28:295-307.

45. Cooper AE: Reconsidering the Tale of Rabbi Yosef Maman and the Bukharan Jewish Diaspora. Jewish Social Studies 2006, 10:80-115.

46. Foltz R: Judaism and the Silk Route. History Teacher 1998, 32:9-16.

47. Kaganovich A: The Mashhadi Jews (Djedids) in Central Asia 1st edition. Berlin: Klaus Schwarz; 2007.

48. Mendelssohn S: The Jews of Asia, especially in the sixteenth and seventeenth centuries (London, New York): K. Paul, Trench, Trubner, E. P. Dutton; 1920.

49. Patterson N, Price AL, Reich D: Population structure and eigenanalysis. PLoS Genet 2006, 2:e190.

50. Yang B, Zhao H, Kranzler HR, Gelernter J: Practical population group assignment with selected informative markers: characteristics and properties of Bayesian clustering via STRUCTURE. Genet Epidemiol 2005, 28:302-312.

51. Paul D: Asymptotics of sample eigenstruture for a large dimensional spiked covariance model. Statistica Sinica 2007, 17:1617-1642.

52. Listman JB, Malison RT, Sughondhabirom A, Yang BZ, Raaum RL, Thavichachart N, Sanichwankul K, Kranzler HR, Tangwonchai S, Mutirangura A, Disotell TR, Gelernter J: Demographic changes and marker properties affect detection of human population differentiation. BMC Genet 2007, 8:21.

53. Spickard PR: Mixed blood: Intermarriage and ethnic identity in twentiethcentury America (Madison, Wis): University of Wisconsin Press; 1989.

54. Benbassa E, Rodrigue A: Sephardi Jewry 1st edition. University of California Press; 2000.

55. Campbell CD, Ogburn EL, Lunetta KL, Lyon HN, Freedman ML, Groop LC Altshuler D, Ardlie KG, Hirschhorn JN: Demonstrating stratification in a European American population. Nat Genet 2005, 37:868-872.

56. Ferreiros-Vidal I, D'Alfonso S, Papasteriades C, Skopouli FN, Marchini M, Scorza R, Migliaresi S, Sebastiani GD, Endreffy E, Mavromati M, KappouRigatou I, Ruzickova S, Dostal C, Schmidt RE, Witte T, Gomez-Reino JJ, Gonzalez A: Bias in association studies of systemic lupus erythematosus susceptibility due to geographical variation in the frequency of a programmed cell death 1 polymorphism across Europe. Genes Immun 2007, 8:138-146.

57. Listman JB: Biases in study design affecting the inference of evolutionary events and population structure in closely-related human populations. 2009 
58. Gelernter J, Panhuysen C, Weiss R, Brady K, Hesselbrock V, Rounsaville B, Poling J, Wilcox M, Farrer L, Kranzler HR: Genomewide linkage scan for cocaine dependence and related traits: significant linkages for a cocaine-related trait and cocaine-induced paranoia. Am J Med Genet $B$ Neuropsychiatr Genet 2005, 136B:45-52.

59. Kaufman J, Yang BZ, Douglas-Palumberi H, Houshyar S, Lipschitz D, Krystal $\mathrm{JH}$, Gelernter J: Social supports and serotonin transporter gene moderate depression in maltreated children. Proc Natl Acad Sci USA 2004, 101:17316-17321.

60. Luo X, Kranzler HR, Zuo L, Wang S, Blumberg HP, Gelernter J: CHRM2 gene predisposes to alcohol dependence, drug dependence and affective disorders: results from an extended case-control structured association study. Hum Mol Genet 2005, 14:2421-2434

61. Stein MB, Schork NJ, Gelernter J: A polymorphism of the beta1adrenergic receptor is associated with low extraversion. Biol Psychiatry 2004, 56:217-224.

62. Jakobsson M, Rosenberg NA: CLUMPP: a cluster matching and permutation program for dealing with label switching and multimodality in analysis of population structure. Bioinformatics 2007 23:1801-1806

63. Rosenberg NA: distruct: a program for the graphical display of population structure. Molecular Ecology Notes 2004, 4:137-138.

64. Rousset F: genepop 4.0 for Windows and Linux. 2007.

65. Guo SW, Thompson EA: Performing the exact test of Hardy-Weinberg proportion for multiple alleles. Biometrics 1992, 48:361-372.

66. Smith MW, Lautenberger JA, Shin HD, Chretien JP, Shrestha S, Gilbert DA, O'Brien SJ: Markers for mapping by admixture linkage disequilibrium in African American and Hispanic populations. Am J Hum Genet 2001, 69:1080-1094.

doi: 10.1186/1471-2156-11-48

Cite this article as: Listman et al., Identification of population substructure among Jews using STR markers and dependence on reference populations included BMC Genetics 2010, 11:48

Submit your next manuscript to BioMed Central and take full advantage of:

- Convenient online submission

- Thorough peer review

- No space constraints or color figure charges

- Immediate publication on acceptance

- Inclusion in PubMed, CAS, Scopus and Google Scholar

- Research which is freely available for redistribution

Submit your manuscript at www.biomedcentral.com/submit
Ciomed Central 